\title{
Did Going Public Impair Moody’s Credit Ratings?
}

\author{
Simi Kedia \\ Professor, Finance and Economics \\ Rutgers Business School \\ Rutgers University \\ Tel no. 8484454195 \\ Email: skedia@business.rutgers.edu \\ Shivaram Rajgopal \\ Schaefer Chaired Professor in Accounting \\ Goizueta Business School \\ Emory University \\ Tel no. 4047279043 \\ Email: shivaram.rajgopal@emory.edu \\ Xing Zhou \\ Asst. Professor, Finance and Economics \\ Rutgers Business School \\ Rutgers University \\ Tel no. 8484454446 \\ Email:xing.zhou@rbsmail.rutgers.edu \\ October 24, 2012

\section{Preliminary and incomplete (first draft) \\ Please do not cite without permission \\ Comments welcome}

\begin{abstract}
We investigate a prominent allegation in Congressional hearings that Moody's loosened its standards for assigning credit ratings after it went public in the year 2000 in an attempt to chase market share and increase revenue. We exploit a difference-in-difference design by benchmarking Moody's ratings with those assigned by its rival S\&P before and after 2000. Consistent with Congressional allegations, we find that Moody's credit ratings for new and existing corporate bonds are significantly more favorable to issuers relative to S\&P's after Moody's initial public offering (IPO) in 2000. Moreover, such relative loosening of credit standards at Moody's after its IPO is more pronounced for clients where Moody's is likely to face larger conflicts of interest: (i) large issuers; and (ii) firms that are more likely to benefit from better ratings, on the margin. Our findings have implications for incentives created by a public offering for capital market gatekeepers and professional firms.
\end{abstract}

We acknowledge financial assistance from our respective schools. All errors are ours alone. 


\section{Did Going Public Impair Moody's Credit Ratings?}

"Many former employees said that after the public listing, Moody's culture changed, it went "from [a culture] resembling a university academic department to one which values revenues at all costs," according to Eric Kolchinsky, a former managing director of Moody's” (The Financial Crisis Inquiry Report 2011, page 207)

\section{Introduction}

The recent financial crisis has spurred an active debate on why the major credit rating agencies failed to downgrade the ratings of structured finance products in a timely manner. Much of the academic debate has focused on the conflicts of interest inherent in the issuer-pay model followed by credit rating agencies (e.g., Mathis, McAndrews, and Rochet 2009, Jiang, Stanford and Xie 2012, Xia 2010, and Bonsall 2012). However, relatively little attention has been devoted to the incentives created by the public ownership structure of rating agencies. In this paper, we investigate whether the quality of credit ratings assigned by Moody's systematically declined after it went public in 2000 .

Moody's was founded in 1900 to produce manuals of performance statistics related to stocks and bonds. The business was acquired by Dun \& Bradstreet in 1962 and spun off as a separate company, organized as Moody's Corporation, on October 4, 2000. In Congressional hearings investigating the culpability of the major credit rating agencies in the financial crisis of 2007, Moody's employees testified that the culture at Moody's changed after it went public. They alleged that after its IPO, Moody’s encouraged an environment where employees were asked to focus on revenues and market share such "that they looked the other way, trading the firm's reputation for short term profits” (The Financial Crisis Inquiry Report 2011, page 207). ${ }^{1}$

To study the impact of Moody’s IPO on its credit ratings, we compare the difference in its ratings of corporate bonds before and after it went public in 2000. The period prior to going public

\footnotetext{
${ }^{1}$ Similar concerns were raised when Goldman Sachs went public. For instance, one partner was worried that "the public company could never replicate the close-knit culture of a partnership, where financial rewards are measured in lifetimes instead of months." (Kahn 1998).
} 
(“pre-public period”) spans 1995 to 1999, and the period after going public (“post-public period”) extends from 2001 to 2005. To control for potential time variations in corporate credit rating standards (Becker and Milbourn 2011, Alp 2012,) and self-selection in the nature of corporate bonds issued in the two periods, we employ a difference-in-difference methodology. In particular, we benchmark Moody's ratings for a common set of corporate bonds to those assigned by its closest rival, Standards \& Poor (S\&P), and then evaluate whether the changes in Moody's ratings relative to S\&P’s ratings, on average across all corporate bonds, were laxer after Moody’s IPO than before.

We begin by comparing credit ratings on new corporate bonds issued in the pre-public period and the post-public period that were rated by both Moody's and S\&P. It is worth noting that although the Financial Crisis Inquiry Commission (FCIC) was mainly concerned with Moody’s push for market share of structured debt products such as mortgage backed securities (MBS) and collateralized debt obligations (CDOs), we instead study the impact of Moody's IPO on its ratings for corporate bonds. This is because most corporate bonds (99\%) are rated by both Moody's and S\&P creating a sample of comparable securities with little selection bias. By contrast, many structured finance products are not rated by both Moody’s and S\&P. Furthermore, corporate bonds are an established product with a long time series of data, whereas there is relatively little issuance of MBS and CDOs in the pre-public period, making a difference-in-difference test difficult to implement. Moreover, finding bias in ratings of corporate bonds is more difficult, given that it is an older and a more mature market than MBS and CDOs, and hence our tests are more stringent. Finally, understanding rating agencies' standards for rating corporate bonds is important, given the influence of bond credit ratings on a firm's cost of debt and capital structure decisions (e.g., Kisgen 2006 and Kisgen and Strahan 2010).

We obtain data on new corporate bond issues and their initial ratings by Moody’s and S\&P from the Mergent's Fixed Income Securities Database (FISD). For each new issue, we create a variable, RatingDiff, which is the S\&P's numerical rating minus the Moody’s numerical rating for 
the bond issue. As more favorable ratings have smaller numerical values, a positive value of RatingDiff implies that Moody's assigned a more favorable rating than S\&P for the new issue. The average value of RatingDiff for the 5,722 new bond issues in the pre-public period is -0.302 . This implies that prior to its IPO, Moody's, on average, assigned tougher ratings than S\&P. The mean value of RatingDiff for the 2,783 new bond issues in the post-public period rises to 0.286 , suggesting that in the period after going public, Moody's reversed its conservative policy and assigned more favorable ratings than S\&P. The change in these differenced ratings, of more than half a notch (0.302+0.286), before and after Moody’s IPO is statistically significant at the $1 \%$ level. The relative loosening of Moody's ratings is also observed for (i) median values of RatingDiff; (ii) both investment-grade and high-yield bonds; and (iii) after controlling for both issue and issuer specific characteristics. We also examine if this relative loosening of Moody credit rating is due to its actions or due to an increase in conservatism by S\&P. We find no evidence of significant changes in the ratings assigned by S\&P following Moody’s IPO in 2000. This result suggests that the relative decline of Moody's ratings is primarily due to Moody's becoming laxer and not attributable to a significant change in S\&P's ratings.

The pressure on the rating agencies to compromise the quality of ratings is likely higher for issuing firms that account for a larger share of the credit rating agencies' revenues. Therefore, we investigate whether large issuers of corporate bonds are likely to experience a greater loosening of credit ratings by Moody's, relative to S\&P. Consistent with this conjecture, we find that though the large issuers got a tougher rating from Moody's relative to S\&P in the pre-public period, they received a relatively more favorable rating from Moody’s in its post-public period.

We also identify bonds whose credit ratings are on the margin and can hence benefit from a better rating from Moody’s. Bongaerts, Cremers and Goetzmann (2012) document that firms with lower ratings often shop for better ratings from other agencies to serve as a tiebreaker. Among all the bonds in any rating class of S\&P, the bonds at the top of the rating class are those with the highest operating profits, and these could potentially take advantage of a higher credit rating from 
Moody's. We find that prior to going public, Moody's was relatively tougher on these bond issuers, but tended to go easy on such issuers after its IPO.

We next investigate Moody’s rating standards on outstanding bonds following its IPO. One way to address this question is to examine whether Moody's became relatively slower in downgrading bonds after it went public. However, comparing the timeliness of rating changes across rating agencies is challenging since rating changes by different rating agencies often occur at different levels and with different magnitudes. Therefore, it is difficult to identify the same rating change by Moody's and S\&P, and compare which agency is faster in rating action. To account for these disparate magnitudes and timings of ratings changes, we compute a new measure that captures, on a daily basis, whether Moody's had a laxer rating than S\&P. The resultant daily indicator variable is aggregated over the year to capture the fraction of the year for which Moody's had a laxer rating. Our measure, LeadTimeDiff, is the difference in the fraction of the year where Moody's rating is laxer minus the fraction of the year where S\&P's rating is laxer, for an outstanding bond. A positive value of LeadTimeDiff implies that, on average, Moody's has a higher number of days with a laxer rating on outstanding bonds relative to S\&P.

We find that LeadTimeDiff is significantly higher in the post-public period. Furthermore, we show that LeadTimeDiff in the post-public period is significantly higher for (i) bonds issued by large issuers; and (ii) bonds that are on the margin, as described earlier, and would hence gain significantly more from a better rating. In summary, after going public, Moody's tended to have better ratings than S\&P for outstanding bonds as well.

We perform several robustness tests. One potential question relates to the impact of the financial crisis of 2007 given that our reported tests only cover the post-public period of 2001 to 2005. To shed light on this issue, we include the years of the financial crisis and extend the postpublic period from 2001 to 2009. For symmetry, the pre-public period is also extended to cover the years 1991 to 1999. Using these extended time windows, we continue to find that Moody's ratings, on both new issues, as well as outstanding bonds, are more favorable than S\&P's after it went 
public. We also investigate whether our results hold for a shorter time period around the decision to go public. The stock market induced pressure from going public and the consequent change in culture potentially takes time to leave its footprint on ratings. Although we expect the effect of going public on ratings to be stronger over a longer time period, we study the one year period before (1999) and after (2001) going public to examine sensitivity of our results. We continue to find a significant easing in Moody's ratings, relative to S\&P, in the year after it went public, pointing to a potentially causal link between the Moody’s IPO and it impact on ratings.

Another potential concern is that the results are driven by our choice of S\&P as the benchmark. Hence, we also estimate our results using Fitch’s ratings as a benchmark. Unlike S\&P, Fitch is not an ideal benchmark because (i) it is much smaller than Moody's; and (ii) Fitch, itself, experienced significant ownership changes in 2000 when it acquired Duff and Phelps, a smaller, publicly listed rating agency. Despite such contamination, we find significant evidence that even relative to Fitch, Moody's assigned more favorable ratings on both new issues and outstanding issues in the period after it went public.

Our paper contributes to the existing literature by documenting the potential impact of stock market pressures on the quality of credit ratings at Moody's subsequent to its IPO. Our findings have implications for the impact of ownership structures on the independence of gatekeepers to financial markets such as auditors, lawyers and underwriters. Traditionally, these gatekeepers have been organized as privately-held companies or partnerships (e.g., the Big Four audit firms) to avoid potential conflicts between clients and public shareholders. Our results suggest that such conflicts are real and can potentially impact the independence of gatekeepers in evaluating their clients’ prospects.

The remainder of the paper is organized as follows. Section 2 discusses the background, and Section 3 explains the research design. Section 4 reports the data and empirical analyses. Section 5 conducts several robustness tests on our results and Section 6 offers concluding remarks. 


\section{Background and Congressional Allegations}

\subsection{Other gatekeepers are privately held}

Gatekeepers such as lawyers, accountants and finance professionals, who assist the company in raising public funds, are crucial to the smooth operation of capital markets. An interesting question to consider is why most gatekeepers, such as auditors and lawyers, are organized as privately owned enterprises. An obvious answer lies in the potential conflict of interest between the gatekeeper's clients and its shareholders. For instance, the prospectus of the first publicly traded law firm in the world, Slater and Gordon, listed on the Australian Stock Exchange in March 2007 includes the following caveat: ${ }^{2}$

"Lawyers have a primary duty to the courts and a secondary duty to their clients. These duties are paramount given the nature of the company's business as an incorporated legal practice. There could be circumstances in which the lawyers of Slater \& Gordon are required to act in accordance with these duties and contrary to other corporate responsibilities and against the interests of shareholders or the short-term profitability of the company. ${ }^{3 \text { " }}$

Debuse (2006) argues that outside, especially public, ownership of a law firm creates conflicts between clients and shareholders. In particular, it is hard to reconcile the key features of a "profession” such as autonomy, the ability to self-regulate through peer review and ethical codes of conduct with the pressures imposed by public ownership on the maximization of profits. Going public would jeopardize the "partnership" ethos of a firm which refers to "collaborative efforts in which goals are shared and at least some measure of mutual participation is the expectation” (Hillman 2005). In fact, the American Bar Association's House of Delegates objected to public ownership in the early 1980s because they were concerned that non-lawyers will interfere with lawyers’ exercise of professional judgment (Debuse 2006).

\footnotetext{
${ }^{2}$ Publicly owned law firms are legally prohibited in the United States.

${ }^{3}$ We could not find a similar caveat in Moody’s prospectus or its $10-\mathrm{K}$ right after it went public.
} 
Adams and Matheson (2008) suggest that these arguments have no merit, since a publicly owned law firm would succeed in the long term only by providing sound legal judgment to its consumers. Because the firm's stock price would incorporate the public law firm's reputation, lawyers would have no incentive to allow profit considerations to interfere with their professional independence and judgment, especially when these lawyers are compensated via stock or stock options. They go on to point out that the pressure to maximize profits is already intense, even at privately held law firms. ${ }^{4}$

Although providing credit ratings is not considered a profession, as per the classic definition of the term, many of the concerns listed in the context of a publicly owned law firm potentially apply to Moody’s as well. More importantly, there is virtually no empirical evidence on the impact, positive or negative, of the act of going public and the consequent stock market induced pressure on a gatekeeper's decisions. We address this important gap in the literature.

\subsection{Literature on the negative impact of going public}

The literature suggests two reasons why going public might create incentives for the public firm to deviate from the "first best" level of outcomes. First, going public necessarily splits ownership from management (Berle and Means 1932, Jensen and Meckling 1976), which, in turn, can create agency problems when the interests of the manager diverge from those of the owners. One version of this agency problem is highlighted in the models of "managerial myopia" such as those advocated by Stein (1989). He suggests that the public-firm's manager will make decisions that deviate from "first best" decisions if he has utility for the firm's short-run stock price. Graham, Harvey and Rajgopal (1995) find survey evidence that a majority of Chief Financial Officers (CFOs) would not be averse to giving up positive net present value projects to meet analyst-consensus estimates of quarterly earnings. Bhojraj et al. (2009) show that firms that barely beat analysts' earnings forecasts cut discretionary $R \& D$ and advertising spending to avoid the

\footnotetext{
${ }^{4}$ The trend of audit firms being organized as limited liability partnerships (LLPs) is related but not directly on point here. LLPs limit the liability of any one partner but continue to suffer from the same limits on raising capital as a traditional partnership.
} 
short-run stock price decline stemming from missing earnings forecasts (Skinner and Sloan 2002), although such cuts lead to underperformance over longer horizons. Asker, Farre-Mensa and Ljungqvist (2012) find that publicly listed firms invest less and are less responsive to changes in investment opportunities compared to similar, matched private firms, especially in industries in which stock prices are particularly sensitive to current earnings. Several other papers document that managers with agency-related incentives cut $R \& D$ or marketing expenditure (e.g., Baber et al. 1991, Dechow and Sloan 1991, Bushee 1998, Roychowdhury 2006, Mizik and Jacobsen 2007, Cohen, Mashruwala and Zach 2009, and Chapman and Steenburgh 2011).

Second, the liquidity associated with the stock's listing on public exchanges also makes it easier for concentrated shareholders to sell rather than hold the stock, monitor the firm and force value-increasing changes on management (Bhide 1993). By contrast, privately held firms are usually owned by holders with concentrated holdings, which are inherently illiquid. These characteristics, on the margin, create incentives for owners in private firms to exercise better governance of the manager's actions.

In the context of our paper, it is worth noting that, S\&P was a $100 \%$ owned subsidiary of McGraw Hill. The 2001 proxy statement filed by Moody's right after it went public, lists two concentrated owners who hold at least 5\% of its shares: (i) Harris Associates LP at 5.28\% and (ii) Berkshire Hathaway at $14.98 \%$. That is, post spin-off, Moody's ownership was diffuse. In particular, Berkshire is known for a hands-off approach in managing its investees (Bowen et al. 2012). Indeed, Warren Buffett (2010) testified to the FCIC that he had no knowledge of how Moody’s assigns ratings.

\subsection{Impact of going public on Moody's: employee testimonials}

Before going public, Moody’s had branded itself with notions of integrity, commitment, and expertise. ${ }^{5}$ One of the analysts, during hearings conducted by the FCIC described the

\footnotetext{
${ }^{5}$ Charlie Munger, complimented the Moody's brand at the 2000 Berkshire Hathaway annual meeting: "Moody's is like Harvard, a self-fulfilling prophecy."
} 
corporate culture at Moody’s before going public as follows: “Moody’s analysts were proud to work for what they believed was by far the best of the rating agencies. They viewed Moody's competitors as a very distant second in quality and ratings integrity” (Froeba 2010). Until that time, Moody's had an extremely conservative analytical culture (Permanent Sub Committee on Investigations 2011, page 273). A 1994 article in Treasury and Risk Management magazine entitled “Why Everyone Hates Moody’s” concluded that “ingrained in Moody’s corporate culture is a conviction that too close a relationship with issuers is damaging to the integrity of the ratings process” (McLean and Nocera 2010, page 114).

However, the culture at Moody's allegedly changed after it went public in 2000, with the focus shifting to improving revenues and market share. Froeba (2010) testified that "as long as market share and revenue were at issue, Moody's best answer could never be much better than its competitors' worst answers.” The Wall Street Journal (April 11, 2008) discusses an anecdote where Brian Clarkson, a managing director, quadrupled Moody’s market share in the residential mortgage backed securities group by simply firing (or transferring) nearly all the analysts in the group and replacing them with analysts willing to apply a new, potentially laxer, rating methodology. Gary Witt, a former team managing director covering U.S. derivatives, described the cultural transformation under Clarkson: "My kind of working hypothesis was that [former chairman and CEO] John Rutherford was thinking, 'I want to remake the culture of this company to increase profitability dramatically [after Moody’s became an independent corporation],' and that he made personnel decisions to make that happen, and he was successful in that regard. And that was why Brian Clarkson's rise was so meteoric: he was the enforcer who could change the culture to have more focus on market share.” (Financial Crisis Inquiry Report 2011, page 207)

Employees have asserted that the increase in market share, especially for structured products, was achieved in two ways: (i) via fears of reprisal; and (ii) by encouraging investment banker clients. According to employee testimonials, the reprisals consisted of a pattern of rewarding compliant analysts with promotions, bonuses and stock options and intimidating analysts 
that were not compliant with the threat of dismissal. In particular, performance appraisals of analysts valued market coverage, revenue, market outreach, ratings quality, and development of analytical tools. However, evaluating employees on the quality of ratings is difficult in real time as the predictive ability of a rating can take years to validate. Hence, greater emphasis was placed on revenue and market share. Richard Michalek (2010), a former Moody's vice president and senior credit officer, testified to the FCIC, "the threat of losing business to a competitor, even if not realized, absolutely tilted the balance away from an independent arbiter of risk towards a captive facilitator of risk transfer.”

At the same time, Moody's tried to reach out to their investment banker clients. Froeba (2010) testified that “investment banks had learned that Moody’s would allow them to ask that all of the bank's deals be assigned to the same particularly "flexible” analyst or team of analysts." They had also learned that they could go over the heads of analysts (even of rating committees despite Moody's policies to the contrary) if they should ever really need to do so by appealing directly to Moody’s managers and senior managers.”

Other employees have alleged that Moody's under-invested in compliance related activities after the spin-off. Scott McCleskey, a former chief compliance officer testified: "so Brian Clarkson comes up to me, in front of everybody at the table, including board members, and says literally, 'How much revenue did Compliance bring in this quarter? Nothing. Nothing.' For him, it was all about revenue.” (Financial Crisis Inquiry Report 2011, page 208)

Top officers at Moody's have denied the significant influence of the public spin-off. They have argued (i) that market share was always a focus, before and after going public; and (ii) Moody's failure to spot deficiencies in the structured mortgage products reflected an industry-wide failure to identify such problems. In particular, Moody’s Corporation Chairman and CEO Raymond McDaniel testified that he didn’t see "any particular difference in culture” after the spinoff (Financial Crisis Inquiry Report 2011, page 207). Brian Clarkson explained that Moody’s cares about business, but the quality of ratings matters even more: “I think that Moody’s has always been 
focused on business... but ratings quality, getting the ratings to the best possible predictive content, predictive status, is paramount.” He blamed unforeseen conditions in the housing market when he testified to the FCIC: "we believed that our ratings were our best opinion at the time that we assigned them. As we obtained new information and were able to update our judgments based on the new information and the trends we were seeing in the housing market, we made what I think are appropriate changes to our ratings” (Financial Crisis Inquiry Report 2011, page 208). ${ }^{6}$

\section{Research Design}

To explore whether Moody's standards for assigning credit ratings were loosened following its IPO in 2000, we examine the difference in its ratings of new corporate bond issues during the pre- and post-public periods. Merely comparing Moody's ratings before and after its IPO is subject to obvious criticisms. For instance, rating standards for the industry might have changed over time for reasons unrelated to Moody’s public listing status. Alp (2012) documents a structural shift toward more stringent ratings in credit rating standards in 2002. Becker and Milbourn (2011) find that greater competition from a bigger Fitch negatively impacted standards for credit quality at all rating agencies.

The drive for market share was also emphasized at S\&P, Moody’s primary competitor (Permanent Subcommittee on Investigations 2011). One former S\&P Managing Director testified: "by 2004 the structured finance department at S\&P was a major source of revenue and profit for the parent company, McGraw-Hill. Focus was directed at collecting market share and revenue data on a monthly basis from the various structured finance rating groups and forwarded to the finance staff at S\&P” (Permanent Subcommittee on Investigations 2011, page 276). The hearings

\footnotetext{
${ }^{6}$ In the literature on the potential conflict of interest induced by the "issuer pays" model (e.g., Jiang et al. 2012), skeptics (e.g., Bonsall 2012) have pointed out that the issuer pays model enables the rated company to provide the rating agency with non-public information that might actually make the rating more informative. This "informativeness" defense seems less germane to the incentives imposed on the rating agency by going public. That is, the access to the rated company does not change in our setting for Moody's or for S\&P.
} 
produced several emails where S\&P's management discusses the possibility of easing rating criteria to gain market share. One example of such emails reads: "we are meeting with your group this week to discuss adjusting criteria for rating CDOs of real estate assets this week because of the ongoing threat of losing deals” (Permanent Subcommittee on Investigations 2011, page 276). Several emails suggesting pressure from investment bankers to dilute ratings also surfaced in the hearings. $^{7}$ He, Qian and Strahan (2012) examine a hand collected sample of mortgage backed securities issued between 2000 and 2006 and find that both Moody’s and S\&P issue more favorable ratings to large issuers, who likely generate more business and higher fees for these agencies. Therefore, an alternate hypothesis is that S\&P, Moody's chief competitor, was equally susceptible to maximizing short term profits and to investment banker pressure. That is, the act of Moody's going public, per se, did not affect their incentives to compromise ratings quality.

To address these concerns, we employ a difference-in-difference methodology by benchmarking Moody's rating of a bond to that assigned by S\&P. Specifically, we estimate the difference in the initial ratings provided by both Moody's and S\&P for new bond issues, RatingDiff, by subtracting Moody’s numerical ratings for a bond issue from that assigned by S\&P, and examine how RatingDiff changes around the time when Moody’s went public.

S\&P serves as an ideal benchmark for Moody’s. S\&P was formed in 1941 from the merger of H.W. Poor Co. and the Standard Statistics Bureau. In 1966, it was acquired by The McGraw-Hill Companies and has been a fully owned division of McGraw Hill ever since. S\&P has been the closest competitor to Moody's. Based on the number of ratings reported outstanding, Moody’s and S\&P are the two largest Nationally Recognized Statistical Rating Organizations

\footnotetext{
${ }^{7}$ For instance, an email in which a UBS banker warned an S\&P senior manager not to use a new, more conservative rating model for $\mathrm{CDOs}$ read: "[H]eard you guys are revising your residential mbs [mortgage backed security] rating methodology - getting very punitive on silent seconds. [H]eard your ratings could be 5 notches back of [Moody's] equivalent. [G]onna kill your resi[dential] biz. [M]ay force us to do moodyfitch only cdos!” (Permanent Subcommittee on Investigations 2011, pp. 278).
} 
(NRSROs) designated by the Securities and Exchange Commission (SEC). ${ }^{8}$ Furthermore, as S\&P ownership status did not change over our sample period, any change in S\&P ratings does not reflect market pressures potentially faced by Moody’s after it went public. This difference-in-difference methodology in the context of credit ratings has also been used by Jiang, Stanford, and Xie (2012). ${ }^{9}$ Note that this research design does not imply that Moody's credit ratings have declined or improved on an absolute scale. Rather, the interpretation is whether relative to the S\&P, Moody's ratings became laxer or tougher after it went public.

The second aspect of our research design is the focus on the credit rating of corporate bonds. Recent congressional hearings regarding Moody’s quest to gain market share by loosening rating standards following its IPO were primarily focused on structured products. However, studying corporate bonds instead has several advantages. First, the risk assessment models for corporate bonds are relatively established, unlike those for structured finance products. Hence, it becomes harder to argue that any differences in ratings between Moody's and S\&P are attributable to (i) differential learning about the nature of the financial products between these agencies; or to (ii) important innovations in the structuring and delivery of such products. As Kroezner and Shiller (2011, page 59) argue, corporate bonds are less opaque than structured finance products because there is substantial amount of public information available about corporate debt. Consequently, the “information advantage" that a credit rating agency might have compared to an industry analyst in rating a corporate bond, relative to a structured finance product, is not great. This feature reduces the opportunity Moody's has to be lax, which would make it harder to detect the effect of the IPO on ratings of corporate bonds. Thus documenting the effect in corporate bonds suggests stronger

\footnotetext{
${ }^{8}$ For the year 2010, Moody's and S\&P have approximately 1 million and 1.2 million ratings reported outstanding, respectively, which far exceed those of the third largest rating agency, Fitch, with approximately 500,000 ratings reported outstanding. See SEC (2011).

${ }^{9}$ Jian, Stanford and Xie (2012) use historical data between 1971 and 1978 to examine the impact on ratings when S\&P adopted the issuer-pays business model. In a difference-in-difference setting, they use Moody's rating for the same bond as a benchmark. The report that S\&P assigns better rating once it switches to collecting fees from issuers.
} 
effects on structured products and sheds light on the magnitude of the impact of Moody's going public.

Second, unlike structured finance products, most corporate bonds (99\%) are rated by both Moody’s and S\&P. This creates a sample of comparable securities with little selection bias. Lastly, in the period prior to Moody's IPO examined in this paper (1995-1999), there were relatively fewer issuances of MBSs and CDOs, rendering the use of the difference-in-difference methodology extremely difficult for structured finance products.

A skeptic can wonder whether an examination of corporate bonds, as opposed to structured products, has any power to detect the impact of Moody's IPO on its ratings. McLean and Nocera (2011, page 116) report that there had long been tension between the corporate bond side of Moody's and its structured finance side. However, the rapid promotions of Brian Clarkson, referenced earlier, signaled that the culture advocated by the structured finance side had won. Bond analysts, even in the pre-IPO days, regularly faced pressure to issue favorable ratings, but Moody's had always backed them when they resisted. After Clarkson's ascension, the corporate bond side was unable to resist the pressure to be favorable to issuers. Hence, we expect to find statistical and economic power in our analysis of corporate bonds with the caveat that the impacts we document could potentially be even higher for MBS and CDOs.

\section{Data and Results: New Issues}

We obtain data on bond characteristics, such as issue size, offering date, and maturity date, as well as the history of credit rating changes by Moody's and S\&P from the Mergent's Fixed Income Securities Database (FISD). We begin by studying new bond issues during the pre- and post- public periods. In particular, we examine the potential differences between the initial credit ratings assigned by Moody’s and S\&P for each new bond issue. For all firms covered by both CRSP and Compustat, we retrieved the list of new bond issues rated by both Moody's and S\&P 
from 1995 to 2005 but excluding 2000. ${ }^{10}$ This results in a sample of 30,484 bonds issued by 903 unique firms. However, a substantial fraction of these new bond issues were made by Freddie Mac and Fannie Mae, and almost all these bonds received an AAA rating from both the rating agencies. Eliminating these government agency bonds reduces our sample to 8,505 new bond issues made by 901 firms. $^{11}$

Table 1 presents the credit ratings categories used by Moody’s, the equivalent ratings by S\&P, and the distribution of our sample new issues across these categories. There are a total of 21 rating categories for both Moody’s and S\&P. For ease of comparison, a numeric value is assigned to each notch of Moody's credit rating, with 1, 2, 3, 4, .. denoting Aaa, Aa1, Aa2, Aa3, ..., respectively. Note that more favorable ratings have smaller numerical values. We find that a substantial fraction of the new issues are investment-grade with very few new issues in the highest or lowest credit quality rating. Table 2 reports that the mean (median) issue size is $\$ 141$ million (\$50 million), and the average time to maturity is eight years. Not surprisingly, firms issuing debt are large, as the average issuer's market value (sum of the market value of equity and the book value of debt) is $\$ 94$ billion, though the median issuer's market value is much smaller at $\$ 39$ billion.

\subsection{Univariate analysis}

To study the difference in the initial ratings assigned by Moody’s and S\&P for new issues, we create the variable RatingDiff, which is the numerical value of the S\&P rating minus the numerical value of the Moody's rating for the same bond issue. As favorable ratings are coded as

\footnotetext{
${ }^{10}$ FISD assigns a unique Issuer ID to each issuing firm. For each Issuer ID, we first identify the list of associated unique 6-digit issuer CUSIPs. We then match the CRSP and Compustat information to all bonds with the same Issuer Id as long as one of the Issuer ID's 6-digit firm CUSIP is covered in CRSP and Compustat at the time of issuance. Further, we exclude bonds where the initial rating by Moody's and S\&P are different by four or more notches. This mismatch is most likely attributable to errors but such mismatches account for less than $1 \%$ of the bond issues.

${ }^{11}$ The results in this paper hold when we expand our sample to include bonds issued by Freddie Mac and Fannie Mae. Results are not reported for brevity, but are available upon request.
} 
smaller values, a positive value of RatingDiff means that Moody's rated the new issue as higher credit quality than S\&P.

As seen in Table 3, in the pre-public period, there were 5,722 new issues with a mean RatingDiff of -0.302 . The negative number implies that Moody's assigned, on average, a tougher credit rating than S\&P in the five years prior to going public. The average RatingDiff in the postpublic period, however, is 0.286, implying that in the five years following its IPO, Moody's, on average, assigned a laxer credit rating relative to S\&P. The move from -0.302 in the pre-public period to the 0.286 in the post-public period is statistically significant at the $1 \%$ level. In sum, Moody’s was significantly more likely to assign a laxer rating of more than half a notch relative to S\&P in the years after its IPO.

We also examine how RatingDiff changes over the individual years around Moody’s IPO. Figure 1 shows that the average value RatingDiff was consistently negative in the pre-public period of 1995 to 1999 . After the IPO in 2000, the average RatingDiff approaches to zero in 2001 and becomes progressively more positive in 2002 and years after that. The size of the change from 1999 to 2001 implies an immediate shift in the conservative culture of Moody's due to market pressures from going public. The positive values of RatingDiff for the years after 2001 suggest that such loosening in rating standards gets greater as time progresses.

To ensure that the results are not driven by a few extreme observations, we also examine the median values of RatingDiff. Although the median of RatingDiff is zero for both periods, the distribution of RatingDiff moves significantly towards the positive end, or towards laxer ratings by Moody’s after its IPO. To make sure that this relative loosening of Moody’s standards after its IPO is not restricted to a few classes of bonds, we examine the rating differences separately for investment-grade and high-yield bonds. As shown in Table 3, Moody's relatively lax standards post-IPO are apparent in all cases. For the subsample of bonds which received a high-yield rating from at least one of the two agencies, high-yield category, we find that Moody's is tougher than S\&P both before and after the IPO, though it is relatively laxer after the IPO. This finding 
indicates that Moody’s comprised its rating quality more for investment-grades bonds, which tend to be issued by larger issuers, and are subject to more conflicts of interest.

\subsection{Multivariate analysis}

The univariate tests yield significant evidence consistent with the Congressional allegations. In this section, we perform multivariate analyses to ensure that the finding of significant laxer ratings by Moody's following its IPO, relative to those by S\&P, hold up after controlling for factors that might account for the difference in the ratings assigned by the two agencies.

To capture the impact of the IPO on RatingDiff, we create a dummy variable, post2000Dum, that takes the value of one for all bonds issued after 2000, i.e., in the post-public period, and zero otherwise. We then regress RatingDiff on post2000Dum. If Moody's loosened its standards for assigning credit ratings following IPO, as hypothesized earlier, we would expect the coefficient of post2000Dum to be positive and significant.

In addition, we control for a host of issuer and bond characteristics in line with those employed by prior work (Pinches and Mingo 1973, Kaplan and Urwitz 1979, Blume, Lim and Mckinlay 1998, Campbell and Taskler 2003, and Jiang, Stanford and Xie 2012). Specifically, we include variables pertaining to the issuing firm: (i) the firm's size using the logarithm of the sum of market value of equity and book value of debt (IssuerSize), (ii) leverage which is the ratio of longterm debt to total assets (Leverage); (iii) firm performance using the ratio of operating performance before depreciation to sales (OpMargin); and (iv) firm volatility as measured by the standard deviation of stock returns (Stkretstd). All accounting variables are of annual frequency, belonging to the fiscal year prior to the issuance of the new bond, and issuer volatility is estimated from daily stock returns in the year prior to the new issue. We also include bond specific variables: (i) the logarithm of the par value of the bond issue (IssueSize), (ii) the number of years to maturity (YTM), and (iii) a dummy variable for whether the issue is senior debt (SeniorDum). It is likely that Moody's rating models for issuers or bonds with specific characteristics changes after its IPO, 
relative to S\&P's model. To control for this potential confound, we include interactions of all the control variables with post2000Dum. In summary, we estimate the following empirical model:

$$
\begin{aligned}
\text { RatingDiff }_{i} & =\gamma_{0}+\gamma_{1} \text { post2000dum }_{i}+\sum_{j=2}^{8} \text { ControlVar }_{i}^{j} \\
& +\sum_{j=2}^{8} \text { ControlVar }_{i}^{j} * \text { post2000dum }_{i}+\varepsilon_{i},
\end{aligned}
$$

where ControlVar $r_{i}^{2}$-ControlVar ${ }_{i}^{8}$ refer to IssuerSize, Leverage, OpMargin, Stkretstd, IssueSize, YTM, and SeniorDum, respectively. Consistent with Jiang, Stanford and Xie (2012), we demean the control variables to enable easier interpretation of the intercept and our key explanatory variable post2000Dum, ${ }^{12}$ and adjust standard errors for heteroscedasticity when calculating $p$-values.

As shown in Column I of Table 4, in a simple difference-in-difference setting, the coefficient on post2000Dum is 0.585 and is significant at the $1 \%$ level. This result suggests that, subsequent to its IPO, Moody's ratings get laxer by more than half of a rating notch, which is a magnitude of easing that is both statistically and economically significant. Our results are qualitatively unchanged in column II when we include all the control variables. The coefficient of post 2000 Dum is positive and significant at the $1 \%$ level, and the magnitude is higher at 0.851 .

With respect to the control variables, Moody's is relatively tougher on firms with higher operating margins (coefficient of -0.006) and those with high stock volatility (coefficient of 1.314). Relative to S\&P, Moody’s weighs bond characteristics differently as well. Moody’s assigns better ratings to bond issues that are larger and have shorter maturity while being tougher on senior issues. This tendency is partly reversed in the post-public period. Overall, the results suggest that Moody's model for assessing credit quality based on bond and issuer characteristics significantly changes after its IPO. More important, controlling for this potential change in their credit rating process does not impact the coefficient on post2000Dum. In summary, the evidence

\footnotetext{
${ }^{12}$ We include each control variables deviation from the annual sample average when estimating the model.
} 
supports the findings of the univariate test that Moody's assigns relatively laxer ratings for new bond issues in the years after its IPO.

To explore what causes the relatively laxer ratings by Moody's following its IPO, and also to shed some light on individual rating agencies, we examine ratings assigned by each agency separately. In column III of Table 4, we re-estimate model (1) by using Moody’s ratings, instead of RatingDiff, as the dependent variable. The coefficient of post2000Dum is negative (-0.935) and significant at the $1 \%$ level, suggesting that Moody’s assigns more favorable ratings after its IPO in 2000. However, when we examine the ratings assigned by S\&P (column IV), we find the coefficient of post2000Dum to be $-0,084$, which is not statistically significant at any conventional level. Taken together, these results indicate that the increase in RatingDiff following Moody’s IPO appears to be driven by laxer ratings from Moody’s, rather than stricter ratings from S\&P.

\subsection{Conflicts of interest}

The results documented thus far clearly suggest that Moody's ratings on new issues loosened relative to S\&P's after the year 2000 when it went public. To provide further corroborative evidence on this issue, we identify cases where there is likely to be the greatest product market pressure on Moody's to be lax, i.e., where the conflicts of interest are expected to be the highest.

After its IPO in 2000, Moody’s management was likely to have had greater incentives to keep important clients (such as the larger issuers of bonds) satisfied, as they accounted for a substantial fraction of its current and future business. This is especially so since most of their revenues came from the fees paid by issuers. ${ }^{13}$ We therefore focus on large bond issuers and examine whether there is greater loosening of Moody's ratings for these large issuers after it went public.

\footnotetext{
${ }^{13}$ According to the 2008 Report of the « Autorité des marchés financiers » on credit rating agencies (see page 15), fees paid by issuers accounted for $80 \%$ of Moody's revenues in 2007. For McGraw-Hill, which is Standard \& Poor's parent company, it was 33\%.
} 
Large issuers are identified based on issue size and frequency of issue. This empirical filter has the added advantage of capturing Moody's payment model which includes both a fixed payment for a bond issue and a variable fee based on the size of the bond issue. A bond issue is classified as large if it is greater than the median size of all bond issues in the past three years. An issuer is classified as large if the par value of all bonds issued in the last three years is above the median for the sample. The dummy variable used to capture higher conflicts of interest, referred to as HighConfDum, takes the value of one if the bond issue is large and is issued by a large issuing firm, and zero otherwise. We then include both HighConfDum, and the product of HighConfDum and post2000dum as explanatory variables for RatingDiff and estimate the following model:

$$
\begin{aligned}
\text { RatingDiff }_{i} & =\gamma_{0}+\gamma_{1} \text { post2000dum }_{i}+\gamma_{2} \text { HighConfDum }_{i} \\
& +\gamma_{3} \text { HighConfDum }_{i}^{*} \text { post2000dum }_{i} \\
& \sum_{j=4}^{10} \text { ControlVar }_{i}^{j}+\sum_{j=4}^{10} \text { ControlVar }_{i}^{j} * \text { post2000dum }_{i}+\varepsilon_{i},
\end{aligned}
$$

where all control variables from model (1) are included in estimation.

As shown in Column I of Table 5, the coefficient of the interaction of HighConfDum with post2000Dum is positive and significant (coefficient $=0.308$, $p$-value $<1 \%$ ), and the coefficient of HighConfDum is negative and significant (coefficient $=-0.205$, $p$-value $<1 \%$ ). That is, before its IPO, Moody’s was relatively tougher on these large issuers. However, Moody's became significantly laxer towards these large issuers after going public in 2000. The coefficient of post2000Dum continues to be positive and significant suggesting that though the relatively loosening of credit ratings after going public is seen for all new issues, it was significantly higher for new large issues by large issuers.

Next, we identify bond issues that are on the margin and could benefit from getting a better rating. In particular, we examine all new issues in a rating class assigned by S\&P. Among the issuers in any rating class, some are relatively more profitable and almost qualify for a better rating relative to the one assigned to them by S\&P. Obtaining such a better rating from a competitor such 
as Moody's is likely to make a substantial difference to these issuers, and is also likely to translate into a better relationship for Moody's with the issuer. Hence, we expect a greater loosening of credit ratings by Moody's for such marginal cases after it went public. The identification of high conflict of interest clients based on this strategy is motivated by Jiang, Stanford and Xie (2012). To seek out the best issuers in any S\&P rating class, we use the issuers' operating profits (operating income before depreciation divided by sales) in the year before the new issue. If the operating profits of the issuer are above the median of all issuers in the S\&P rating class, then we identify it as a client with greater conflicts of interest. HighConfDum is then re-calculated using this criteria.

As seen in column II of Table 5, the coefficient on the HighConfDum, newly defined based on operating profits, is negative and significant (coefficient $=-0.451, p$-value $<1 \%$ ), and its interaction with post2000Dum is positive and significant (coefficient=0.368, $p$-value $<1 \%$ ). Consistent with previous results, Moody's is relatively tougher on these high conflict of interest issuers in the period prior to 2000 but loosens up after 2000. The coefficient of post2000Dum continues to be positive and highly significant under this new definition of HighConfDum.

\subsection{Outstanding Bonds}

The preceding section provides consistent evidence on the relative loosening of Moody's credit ratings of bond issuers after its IPO in 2000. In this section, we examine whether this relative loosening of credit ratings is also seen in the ratings on outstanding bonds.

One direct approach to address this question is to compare the timeliness of rating changes across rating agencies before and after Moody's went public. However, examining which agency is faster is rating action requires the identification of same rating changes by both agencies, which is challenging since rating changes by different rating agencies often occur at different levels and with different magnitudes. For instance, consider a typical case with three rating events: (i) S\&P downgrades a bond from AA- to A+ in May 1999; (ii) Moody's downgrade the same bond by two notches, from AA to A, in July 1999; and (iii) finally, 
S\&P downgrades the bond again from A+ to A- in September 1999. This example highlights the difficulty in identify a rating change from the same level and with the same magnitude by both rating agencies, rendering the direct comparisons in the timeliness of rating migrations across rating agencies rather difficult.

To capture these disparate levels, magnitudes and timing in rating changes, we estimate a measure of the differences between Moody’s and S\&P ratings on a daily basis. Specifically, we create a dummy variable, Moody'sLeadDum, which is equal to one if Moody's assigned a laxer rating than S\&P for a particular bond on a particular day, and zero otherwise. S\&PLeadDum is created in a similar way. To capture the fraction of the year for which Moody's rating is laxer than S\&P's, we create a new variable, LeadTimeDiff, which is the average value of Moody'sLeadDum for the year minus the average value of the S\&PLeadDum over the same year for the same bond. A positive value of LeadTimeDiff suggests that Moody's has a laxer rating than S\&P for a higher fraction of the year for that bond. Note that the average value of LeadTimeDiff should be zero if (i) there are no differences between the ratings assigned by the two agencies for the bond; and (ii) the differences between the ratings assigned by these two agencies were randomly distributed across bonds and time.

Model (1) is re-estimated by using LeadTimeDiff as the dependent variable and the results are presented in Table 6. As shown in column I, the coefficient of post2000Dum is positive and highly significant (coefficient $=0.301, p$-value $<1 \%$ ), confirming that Moody's had a more favorable rating than S\&P, on average, for outstanding bonds after its IPO in 2000.

Similar to the earlier analysis with new bond issues, we examine whether the loosening of Moody's credit ratings is more likely to occur for clients where Moody’s has a higher conflict of interest. The first proxy for high conflicts of interest is large issuers as defined in the previous section. As with new issues, we again find that the coefficient on the interaction of HighConfDum and post2000Dum is positive and significant (coefficient $=0.052, p$-value $=1 \%$ ), and the coefficient of HighConfDum is negative and significant (coefficient $=-0.128, p$-value $<1 \%$ ). These results 
suggest that Moody's was relatively tougher on these clients with high conflict of interest prior to going public, and it became significantly laxer after its IPO. The coefficient of post2000Dum continues to be positive and significant (coefficient $=0.257$, $p$-value $<1 \%$ ), implying that Moody’s loosening is seen broadly across bonds although such loosening is significantly higher for the large bond issuers. Similar results are found when we use operating profits to identify clients with high conflict of interests in Column III.

\section{Robustness Tests}

In this section, we examine the robustness of our results to three specification checks. In particular, we investigate the sensitivity of our results to (i) longer time periods that include the financial crisis; (ii) shorter time windows that focus more narrowly on the IPO event; and (3) using Fitch ratings as an alternative benchmark.

\subsection{Impact of the financial crisis}

We investigate whether our results are robust to the inclusion of the unique circumstances associated with the financial crisis. Our research design thus far has only includeed five years before and after the 2000 IPO and hence excludes the years 2007 to 2009, the period of financial crisis. To address this issue, we re-estimate our results using a longer window around the IPO, i.e., 1991 to 2009. Specifically, we now define the pre-public period as the nine-year period from 1991 to 1999 , and the post-public period where the post2000dum is set to one for the years from 2001 to 2009. As seen in panel A of Table 7, studying the nine year window before and after the IPO does not impact our results. The coefficient of post2000dum continues to be positive and highly significant for both new issues and outstanding issues.

\subsection{Shorter time period around IPO}

In the analysis reported so far, our research design has focused on studying five years before and after Moody's IPO to account for the fact that the resulting stock market induced pressure to report higher revenues may not have been instantaneous. However, a longer time 
period opens up the possibility of confounding events. Therefore, we also examine the effect of Moody’s going public over a short time period, i.e. from 1999 to 2001, considering ratings for the one year before and after Moody’s went public.

The results for both new issues and outstanding issues for this short time period are displayed in panel B of Table 7. The coefficient of post2000dum for new issues is 0.475 and for outstanding issues is 0.114 . Both are highly significant. In the shorter time period, the results again clearly point towards a loosening of Moody credit ratings after going public. This finding indicates potential causality between Moody’s IPO and its laxer credit ratings.

\subsection{Benchmarking against Fitch}

Fitch is currently the third largest credit rating agency in the world. It was acquired by IBCA Limited of London in 1997 and in 2000 it acquired Duffs and Phelps, a publicly listed credit rating agency. The acquisition in 2000, the year of Moody’s IPO, raises concerns about the suitability of Fitch as a benchmark. Nevertheless, we identify all new issues as well as outstanding issues that had both a Moody's ratings as well as a rating by Fitch. After ensuring that data on control variables are available, we have a sample of 5,851 new issues over the period 1995 to 2005 (excluding 2000) and 32,428 bond-years for the analysis of outstanding bonds.

The variable RatingDiff is now defined as the numerical equivalent of Fitch's rating minus the numerical equivalent of Moody’s rating. A positive value of RatingDiff implies that Moody’s has a more favorable rating than Fitch, similar to the previous sections. We find that Moody's assigned significantly more favorable ratings to new bond issues relative to Fitch in the years after 2000 in comparison the years prior to 2000 (see Panel C of Table 7). The coefficient of post2000Dum is positive and highly significant at the $1 \%$ level. To capture rating differences on outstanding bonds, we define LeadTimeDiff as the percentage of days in a year that Moody's has a laxer rating minus the percentage of the days in the year that Fitch has a laxer rating, and reestimate model (2). The coefficient of post2000Dum for this estimation is again positive and highly 
significant at the $1 \%$ level. In summary, even relative to Fitch, Moody’s assigned more favorable ratings to new issues as well as to outstanding issues in the years after its IPO in 2000.

\subsection{Conclusions}

In this paper, we investigate Congressional allegations that going public transformed Moody’s from a conservative rating agency to one focused on market share and short term profits. To examine this allegation, we benchmark Moody’s ratings to those of its main competitor, S\&P, which did not undergo a change in its ownership status over this time period. We find significant evidence, both in economic and statistical terms, that Moody's was more likely to assign favorable ratings relative to S\&P for new corporate bond issues in the period after its IPO. A similar trend is also seen in the ratings of outstanding bonds, with Moody's being significantly laxer in the years after its IPO. Moreover, these loose standards are more pronounced in the bonds issued by large issuers, consistent with allegations that Moody's was willing to accommodate its repeat customers

with more favorable ratings. In summary, the evidence is largely consistent with conjectures that the act of going public has impaired the independence and the quality of Moody's credit ratings. Our results have implications for the ownership structure of all capital market gatekeepers. 


\section{REFERENCES}

Adams, E. and J.H. Matheson. 1998. Law firms on the big board?: A proposal for non-lawyer investment in law firms. California Law Review 86: 1-2.

Alp, A. 2012. Structural Shifts in Credit Rating Standards. Forthcoming at Journal of Finance.

Asker, J., J. Farre-Mensa, and A. Ljungqvist. 2012. Comparing the investment behavior of public and private firms. Working paper, New York University.

Baber, W., P. Fairfield, and J. Haggard. 1991. The effect of concern about reported income on discretionary spending decisions: The case of research and development. The Accounting Review 66: 818-829.

Becker, B. and T. Milbourn. 2011. How did competition affect credit ratings? Journal of Financial Economics (1-3): 493-514.

Berle, A., and G. Means. 1932. The Modern Corporation and Private Property (New York, Macmillan).

Bhojraj, S., P. Hribar, M. Picconi, and J. McInnis. 2009. Making sense of cents: An examination of firms that marginally miss or beat analyst forecasts. Journal of Finance 64, 23612388.

Bhide, A. 1993. The hidden cost of stock market liquidity. Journal of Financial Economics 34, 3451.

Blume, M., F. Lim, and A. MacKinlay. 1998. The declining credit quality of U.S. corporate debt: myth or reality? Journal of Finance 53:1389-1413.

Bongaerts, D., M., Cremers and W. Goetzmann. 2012. Tiebreaker: Certification and multiple credit ratings. Journal of Finance (forthcoming).

Bonsall., S. 2012. The informational effects of firm funded certification: Evidence from the bond rating agencies. Working paper, Ohio State University.

Bowen, R., S. Rajgopal and M. Venkatachalam. 2012. Is Warren Buffett's commentary on accounting, governance and investing practices reflected in the investment decisions and subsequent influence of Berkshire Hathaway? Working paper, University of San Diego, Emory University and Duke University.

Buffett, W. 2010. Testimony before the FCIC, Hearing on the credibility of credit ratings, the investment decisions made based on those ratings, and the financial crisis, session 2: Credit Ratings and the Financial Crisis, June 2.

Bushee, B. 1998. The influence of institutional investors on myopic R\&D investment behavior. Accounting Review 73(3): 305-333.

Campbell, J., and G. Taksler. 2003. Equity volatility and corporate bond yields. Journal of Finance 58:2321-2349. 
Cohen, D., R. Mashruwala, and T.Zach. 2009. The use of advertising activities to meet earnings benchmarks: Evidence from monthly data. Review of Accounting Studies.

Chapman, C. and T. Steenburgh. 2011. An investigation of earnings management through marketing actions. Management Science 57(1): 72-92.

Dechow, P. and R. Sloan. 1991. Executive incentives and the horizon problem. Journal of Accounting and Economics 14(1): 51-89.

Debuse, J.R. 2008. Opening at \$25 1/2 is Big Firm U.S.A.: Why America may eventually have a publicly traded law firm, and why law firms can succeed without going public. Journal of Corporation Law 34: 317.

Empson, L. 2007. Your Partnership: Surviving and thriving in a changing world: The special nature of a partnership, in Managing the Modern Law Firm: New Challenges, New Perspectives.

Financial Crisis Inquiry Commission. 2011. Final Report of the National Commission on the Causes of the Financial and Economic Crisis in the United States.

Froeba, M. 2010. Testimony before the Financial Crisis Inquiry Commission. June 2.

Graham, J., C. Harvey, and S. Rajgopal. 2005. The economic implications of corporate financial reporting. Journal of Accounting and Economics 40(1-3): 3-73.

He, J., J. Qian and P. Strahan. 2012. Are all ratings created equal? The impact of issuer size on the pricing of mortgage backed securities. Journal of Finance (forthcoming).

Hillman, R.W. 2005. Law, culture, and the lore of partnership: Of entrepreneurs, accountability, and the evolving status of partners. Wake Forest Law Review 40: 793-94.

Jiang, J., M. Stanford and Y. Xie. 2012. Does it matter who pays for bond ratings? Historical evidence. Journal of Financial Economics 105: 607-621.

Kahn, J. 1998. Plan to go public at Goldman Sachs. New York Times. June 15.

Kaplan, R., and G. Urwitz. 1979. Statistical models of bond ratings: A methodological inquiry. Journal of Business 52:231-261.

Kisgen, D., 2006, Credit Ratings and Capital Structure. Journal of Finance 61, 1035-1072.

Kisgen, D., and P. Strahan, 2010. Do Regulations Based on Credit Ratings Affect a Firm's Cost of Capital? Review of Financial Studies 23, 4324-4347.

Kroezner, R. and R. Shiller. 2011. Reforming U.S. Financial Markets. MIT Press.

Mathis, J., J. McAndrews, and J.-C. Rochet, 2009. Rating the Raters: Are Reputation Concerns Powerful Enough to Discipline Rating Agencies? Journal of Monetary Economics 56, 657-674.

McLean, B. and J. Nocera. 2010. All the Devils are Here: The Hidden History of The Financial Crisis. Penguin Group. 
Michalek, R. 2010. Testimony before the FCIC, Hearing on the credibility of credit ratings, the investment decisions made based on those ratings, and the financial crisis, session 3: The Credit Rating Agency Business Model, June 2.

Mizik, N., and R. Jacobson. 2007. Myopic marketing management: Evidence of the phenomenon and its long-term performance consequences in the SEO Context. Marketing Science 26(3): 361379.

Permanent Subcommittee on Investigations. 2011. Wall Street and the Financial Crisis. Anatomy of a Financial Collapse. Majority and Minority Staff Report.

Pinches, G., and K. Mingo. 1973. A multivariate analysis of industrial bond ratings. Journal of Finance 28:1-16.

Roychowdhury, S. 2006. Earnings management through real activities manipulation. Journal of Accounting and Economics 42(3): 335-370.

SEC. 2011. Summary report of commission staff's examinations of each nationally recognized statistical rating organization.

Skinner, D. and R. G. Sloan. 2002. Earnings surprises, growth expectations, and stock returns or don't let an earnings torpedo sink your portfolio. Review of Accounting Studies 7(2-3): 13806653.

Xia, H. 2010. The issuer-pay rating model and rating inflation: Evidence from corporate credit ratings, Working paper, University of North Carolina. 


\section{Figure 1: Difference in Credit Ratings Assigned by Moody's and S\&P around Moody's IPO in 2000}

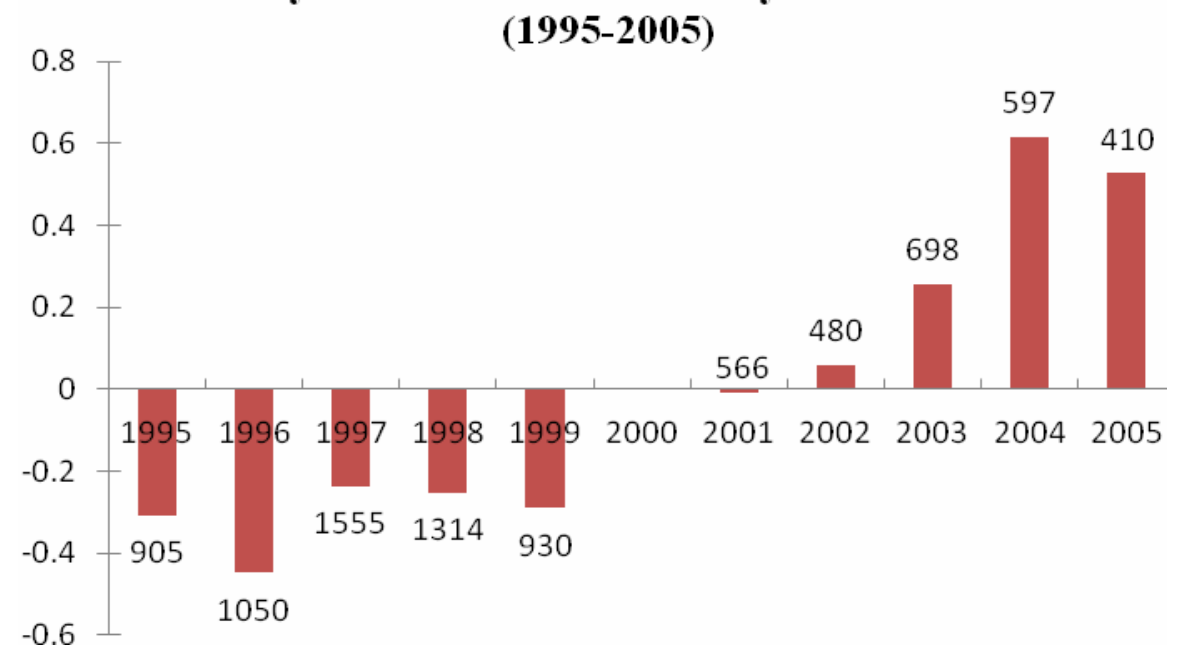

The length of the bar in the figure represents the yearly average of the RatingDiff variable over period around Moody's IPO. RatingDiff is the S\&P's numerical rating minus the Moody's numerical rating for new bond issues, coded as per Table 1 . As smaller numbers correspond to higher ratings, a positive (negative) value of RatingDiff implies that Moody's assigns a laxer (stricter) rating. The number on top of each bar represents the number of new bond issues over which the RatingDiff variable was computed every year. 
Table 1: Numerical Coding of Rating Categories and Frequencies of Such Categories for New Bond Issues

This table presents summary statistics on the different rating categories for Moody's and S\&P and their numerical mapping. Frequency is the percentage of new issues over the period 1991 to 2009 (excluding 2000) that belong to each category.

\begin{tabular}{|c|c|c|c|c|c|}
\hline & \multirow{2}{*}{$\begin{array}{l}\text { Numeric } \\
\text { Rating }\end{array}$} & \multicolumn{2}{|c|}{ Moody's } & \multicolumn{2}{|l|}{ S\&P } \\
\hline & & Credit Rating Letter & $\begin{array}{c}\text { Frequency } \\
(\%)\end{array}$ & Credit Rating Letter & $\begin{array}{c}\text { Frequency } \\
(\%)\end{array}$ \\
\hline \multicolumn{6}{|c|}{ Investment-grade } \\
\hline Highest Quality & 1 & Aaа & 0.21 & AAA & 0.25 \\
\hline \multirow[t]{3}{*}{ Very High Quality } & 2 & Aa1 & 0.07 & $\mathrm{AA}+$ & 0.68 \\
\hline & 3 & $\mathrm{Aa} 2$ & 0.92 & AA & 1.61 \\
\hline & 4 & Aa3 & 17.32 & AA- & 9.68 \\
\hline \multirow[t]{3}{*}{ High Quality } & 5 & A1 & 11.13 & $\mathrm{~A}+$ & 11.57 \\
\hline & 6 & A3 & 22.54 & A & 32.58 \\
\hline & 7 & A3 & 5.62 & A- & 4.83 \\
\hline \multirow[t]{3}{*}{$\begin{array}{l}\text { Minimum Investment } \\
\text { Grade }\end{array}$} & 8 & Baa1 & 8 & $\mathrm{BBB}+$ & 5.02 \\
\hline & 9 & Baa2 & 4.67 & BBB & 4.84 \\
\hline & 10 & Baa3 & 3.01 & BBB- & 3.14 \\
\hline \multicolumn{6}{|c|}{ High-yield } \\
\hline \multirow[t]{3}{*}{ Low Grade } & 11 & Ba1 & 1.72 & $\mathrm{BB}+$ & 1.63 \\
\hline & 12 & $\mathrm{Ba} 2$ & 1.27 & $\mathrm{BB}$ & 7.88 \\
\hline & 13 & $\mathrm{Ba} 3$ & 6.67 & BB- & 1.65 \\
\hline \multirow[t]{3}{*}{ Very Speculative } & 14 & B1 & 5.03 & $\mathrm{~B}^{+}$ & 3.64 \\
\hline & 15 & B3 & 4.96 & B & 5.08 \\
\hline & 16 & B3 & 5.2 & B- & 4.26 \\
\hline \multirow[t]{3}{*}{ Substantial Risk } & 17 & Caa1 & 1 & CCC + & 0.93 \\
\hline & 18 & Caa2 & 0.47 & CCC & 0.55 \\
\hline & 19 & Сaа3 & 0.16 & CCC- & 0.12 \\
\hline \multirow[t]{2}{*}{ Very Poor Quality } & 20 & $\mathrm{Ca}$ & 0.04 & $\mathrm{CC}$ & 0.06 \\
\hline & 21 & $\mathrm{C}$ & 0.00 & $\mathrm{C}$ & 0.00 \\
\hline
\end{tabular}


Table 2: Descriptive Statistics of Firms Issuing Rated New Bonds

Issuer Size is the market value of equity plus the book value of debt. Leverage is long term debt divided by total assets. Operating Margin is operating income before depreciation divided by sales. Stock return standard deviation is the standard deviation of daily stock returns in the year prior. Issue size is the par value of the bond issue. All firm characteristics are measured the year prior to the new issue.

\begin{tabular}{lccc}
\hline & Mean & Median & Std \\
\hline Issuer Size (\$ million) & $93,589.51$ & $38,808.46$ & $117,998.88$ \\
Leverage & 0.27 & 0.21 & 0.19 \\
Operating Margin & 0.22 & 0.43 & 6.58 \\
Stock Return Standard Deviation & 0.06 & 0.02 & 0.15 \\
Issue Size (\$ million) & 141.40 & 50.00 & 291.00 \\
Time to Maturity at Issuance (Years) & 7.75 & 5.76 & 8.03 \\
\hline
\end{tabular}


Table 3: Univariate Comparisons of Ratings of New Issues between Moody's and S\&P

This table presents results of univariate tests for the variable RatingDiff. RatingDiff is the S\&P's numerical rating minus the Moody's numerical rating the new bond issues, coded as per Table 1. As smaller numbers mean laxer ratings, a positive value of RatingDiff implies that Moody's gives laxer ratings. The column "Pre-Moody's IPO" covers all eligible new bonds issued over 1995 to 1999. The column "Post-Moody IPO" includes all eligible new bond issues over 2001 to 2005. "Investment-rade category (IV)" includes all new issues where both Moody's and S\&P assigned an investment grade rating at the time of issuance. "High-Yield (HY)" refers to new issues where both Moody's and S\&P assigned a high yield rating at the time of issuance. "Across IV and HY" refers to the small sample of new issues where one rating agency assigns an investment-grade rating while the other assigns a high-yield rating.

\begin{tabular}{llccc}
\hline & & Pre-Moody's IPO & Post-Moody's IPO & Test (p-value) \\
\hline \multirow{2}{*}{ Full Sample } & Mean & -0.302 & 0.286 & $<.0001$ \\
& Median & 0.000 & 0.000 & $<.0001$ \\
& Nobs & 5,722 & 2,783 & $<.0001$ \\
\hline \multirow{2}{*}{ Investment-grade (IV) } & Mean & -0.189 & 0.425 & $<.0001$ \\
& Median & 0.000 & 0.000 & $<.0001$ \\
\hline \multirow{2}{*}{ High-yield (HY) } & Nobs & 4,076 & 2,150 & $<.0001$ \\
& Mean & -0.567 & -0.158 & 0.000 \\
\hline \multirow{2}{*}{ Across IV and HY } & Median & -1.000 & 582 & 0.057 \\
& Nobs & 1,588 & -0.490 & 0.037 \\
\hline
\end{tabular}


Table 4: Do Moody's Ratings Become Laxer for New Issues after its IPO?

The table presents results from estimating four different specifications of model (1). The dependent variable in columns I and II is RatingDiff and in columns III and IV is the numeric rating by Moody's and S\&P, Moody's Rating and S\&P Rating, respectively. RatingDiff is the S\&P numerical rating minus the Moody's numerical rating. Post2000Dum is a dummy variable that takes the value of one for new bond issued during the post-public period, i.e., from 2001 to 2005 , and zero otherwise. IssuerSize is natural logarithm of total market value. Leverage is the ratio of long-term debt divided by total assets. OpMargin is operating income before depreciation divided by sales. Stkreststd is the standard deviation of daily stock returns in the year prior to the issuance. IssueSize is the logarithm of the par value of the bond issue. YTM is the number of years to maturity. Seniordum is a dummy variable one for senior debt. All accounting variables are measured in the year prior to the new issue. The number below each estimate of the coefficients is heteroscedasticity adjusted robust $p$-value. We cluster standard errors by the issuing firm. ${ }^{* * *},{ }^{* *}$, ${ }^{*}$ represent significance at $1 \%, 5 \%$ and $10 \%$ level, respectively.

\begin{tabular}{|c|c|c|c|c|}
\hline & I & II & III & IV \\
\hline \multirow[t]{2}{*}{ Intercept } & -0.299 & 0.155 & 8.401 & 8.556 \\
\hline & $<.0001$ & 0.088 & $<.0001$ & $<.0001$ \\
\hline \multirow[t]{2}{*}{ post2000Dum } & 0.585 & 0.851 & -0.935 & -0.084 \\
\hline & $<.0001$ & $<.0001$ & $<.0001$ & 0.676 \\
\hline \multirow[t]{2}{*}{ IssuerSize } & & -0.010 & -1.259 & -1.269 \\
\hline & & 0.229 & $<.0001$ & $<.0001$ \\
\hline \multirow[t]{2}{*}{ Leverage } & & -0.105 & 2.755 & 2.651 \\
\hline & & 0.290 & $<.0001$ & $<.0001$ \\
\hline \multirow[t]{2}{*}{ OpMargin } & & -0.006 & -0.026 & -0.032 \\
\hline & & $<.0001$ & $<.0001$ & $<.0001$ \\
\hline \multirow[t]{2}{*}{ Stkretstd } & & -1.314 & 7.397 & 6.083 \\
\hline & & $<.0001$ & $<.0001$ & $<.0001$ \\
\hline \multirow[t]{2}{*}{ IssueSize } & & 0.034 & 0.193 & 0.227 \\
\hline & & 0.002 & $<.0001$ & $<.0001$ \\
\hline \multirow[t]{2}{*}{ YTM } & & -16.560 & -65.638 & -82.198 \\
\hline & & 0.000 & $<.0001$ & $<.0001$ \\
\hline \multirow[t]{2}{*}{ SeniorDum } & & -0.188 & -1.673 & -1.860 \\
\hline & & $<.0001$ & $<.0001$ & $<.0001$ \\
\hline \multirow[t]{2}{*}{ IssuerSize*post2000Dum } & & 0.123 & 0.041 & 0.164 \\
\hline & & $<.0001$ & 0.312 & $<.0001$ \\
\hline \multirow[t]{2}{*}{ Leverage*post2000Dum } & & -0.052 & 1.290 & 1.238 \\
\hline & & 0.751 & 0.021 & 0.021 \\
\hline \multirow[t]{2}{*}{ OpMargin*post2000Dum } & & 0.006 & 0.015 & 0.021 \\
\hline & & $<.0001$ & $<.0001$ & $<.0001$ \\
\hline \multirow[t]{2}{*}{ Stkretstd*post2000Dum } & & 1.725 & 9.575 & 11.300 \\
\hline & & 0.257 & 0.047 & 0.020 \\
\hline \multirow[t]{2}{*}{ IssueSize*post2000Dum } & & -0.106 & -0.012 & -0.118 \\
\hline & & $<.0001$ & 0.797 & 0.003 \\
\hline \multirow[t]{2}{*}{ YTM*post2000Dum } & & 6.859 & 124.945 & 131.804 \\
\hline & & 0.325 & $<.0001$ & $<.0001$ \\
\hline \multirow[t]{2}{*}{ Seniordum*post2000Dum } & & 0.019 & -0.096 & -0.077 \\
\hline & & 0.759 & 0.560 & 0.642 \\
\hline Adjusted R-square & 0.095 & 0.216 & 0.765 & 0.762 \\
\hline $\mathrm{N}$ & 8,505 & 8,505 & 8,505 & 8,505 \\
\hline
\end{tabular}


Table 5: Cross Sectional Variation in Moody's Laxer Ratings Post IPO

The table present results from estimating model (2). The dependent variable is RatingDiff, the S\&P numerical rating minus the Moody's numerical rating. Post2000Dum is a dummy variable that takes the value of one for the years in the post-public period, and zero otherwise. HighConfDum is a dummy variable that is equal to one for bonds with greater conflicts of interest, and zero otherwise. In column I (column II), bonds with greater conflict of interests are those by large issuers (the issuers' profit margin is above the median for that S\&P's rating grade). Other variables are defined as in Table 4 . The number below each estimate of the coefficients is heteroscedasticity adjusted robust $p$-value. We cluster standard errors by the issuing firm. $* * *, * *, *$ represent significance at $1 \%, 5 \%$ and $10 \%$ level, respectively.

\begin{tabular}{|c|c|c|}
\hline & I. Large vs. Small & II: High vs. Low Credit \\
\hline Intercept & 0.291 & 0.228 \\
\hline \multirow{3}{*}{ post2000Dum } & 0.002 & 0.009 \\
\hline & 0.699 & 0.744 \\
\hline & $<.0001$ & $<.0001$ \\
\hline \multirow{2}{*}{ HighConfDum } & -0.205 & -0.415 \\
\hline & $<.0001$ & $<.0001$ \\
\hline \multirow[t]{2}{*}{ HighConfDum*post2000dum } & 0.308 & 0.368 \\
\hline & $<.0001$ & $<.0001$ \\
\hline \multirow{2}{*}{ IssuerSize } & -0.018 & -0.019 \\
\hline & 0.034 & 0.032 \\
\hline \multirow{2}{*}{ Leverage } & -0.077 & -0.066 \\
\hline & 0.427 & 0.515 \\
\hline \multirow{2}{*}{ OpMargin } & -0.006 & -0.005 \\
\hline & $<.0001$ & $<.0001$ \\
\hline \multirow{2}{*}{ Stkretstd } & -1.229 & -1.420 \\
\hline & $<.0001$ & $<.0001$ \\
\hline \multirow{2}{*}{ IssueSize } & 0.081 & 0.047 \\
\hline & $<.0001$ & $<.0001$ \\
\hline \multirow{2}{*}{ YTM } & -18.134 & -14.515 \\
\hline & $<.0001$ & 0.001 \\
\hline \multirow[t]{2}{*}{ Seniordum } & -0.192 & -0.238 \\
\hline & $<.0001$ & $<.0001$ \\
\hline \multirow[t]{2}{*}{ IssuerSize*post2000Dum } & 0.136 & 0.130 \\
\hline & $<.0001$ & $<.0001$ \\
\hline \multirow{2}{*}{ Leverage*post2000Dum } & -0.082 & -0.097 \\
\hline & 0.616 & 0.561 \\
\hline \multirow[t]{2}{*}{ OpMargin*post2000Dum } & 0.006 & 0.005 \\
\hline & $<.0001$ & $<.0001$ \\
\hline \multirow[t]{2}{*}{ Stkretstd*post2000Dum } & 1.728 & 1.879 \\
\hline & 0.257 & 0.223 \\
\hline \multirow{2}{*}{ IssueSize*post2000Dum } & -0.171 & -0.117 \\
\hline & $<.0001$ & $<.0001$ \\
\hline \multirow[t]{2}{*}{ YTM*post2000Dum } & 9.936 & 6.101 \\
\hline & 0.156 & 0.381 \\
\hline \multirow[t]{2}{*}{ Seniordum*post2000Dum } & 0.025 & 0.070 \\
\hline & 0.687 & 0.270 \\
\hline \multirow{2}{*}{$\begin{array}{l}\text { Adjusted R-square } \\
\mathrm{N}\end{array}$} & 0.219 & 0.213 \\
\hline & 8,505 & 8,505 \\
\hline
\end{tabular}


Table 6: Moody's Laxer Ratings with All Bond Issues After its IPO

This table presents the results from re-estimating model (1) where LeadTimeDiff is used as the dependent variable. LeadTimeDiff is the fraction of a year where Moody's assigns a higher rating minus the fraction of a year where S\&P assigns a higher rating. Post2000Dum is a dummy variable that takes the value of one for the years in the post-public period, and zero otherwise. HighConfDum is a dummy variable that is equal to one for bonds with greater conflicts of interest, and zero otherwise. In model 2, bonds with greater conflict of interests are those by large issuers, while in model 3 , bonds with greater conflict of interests are those where the issuers' profit margin is above the median for that S\&P's rating grade. Other variables are defined as in Table 4. The number below each estimate of the coefficients is heteroscedasticity adjusted robust $p$-value. We cluster standard errors by the issuing firm. ***, **, * represent significance at $1 \%, 5 \%$ and $10 \%$ level, respectively.

\begin{tabular}{|c|c|c|c|}
\hline & I & II & III \\
\hline Intercept & -0.041 & 0.080 & -0.048 \\
\hline \multirow[b]{2}{*}{ post2000Dum } & $<.0001$ & $<.0001$ & $<.0001$ \\
\hline & 0.301 & 0.257 & 0.229 \\
\hline \multirow[b]{2}{*}{ HighConfDum } & $<.0001$ & $<.0001$ & $<.0001$ \\
\hline & & -0.128 & 0.011 \\
\hline \multirow[b]{2}{*}{ HighConfDum*post2000dum } & & $<.0001$ & 0.085 \\
\hline & & 0.052 & 0.132 \\
\hline \multirow[b]{2}{*}{ IssuerSize } & & 0.010 & $<.0001$ \\
\hline & 0.016 & 0.020 & 0.015 \\
\hline \multirow[b]{2}{*}{ Leverage } & $<.0001$ & $<.0001$ & $<.0001$ \\
\hline & 0.087 & 0.114 & 0.083 \\
\hline \multirow[b]{2}{*}{ OpMargin } & $<.0001$ & $<.0001$ & 0.000 \\
\hline & -0.005 & -0.005 & -0.005 \\
\hline \multirow[b]{2}{*}{ Stkretstd } & $<.0001$ & $<.0001$ & $<.0001$ \\
\hline & -0.246 & -0.255 & -0.244 \\
\hline \multirow[b]{2}{*}{ IssueSize } & 0.011 & 0.008 & 0.011 \\
\hline & 0.005 & 0.005 & 0.005 \\
\hline \multirow{2}{*}{ YTM } & 0.001 & 0.000 & 0.001 \\
\hline & 0.019 & 0.019 & 0.019 \\
\hline \multirow[b]{2}{*}{ Seniordum } & $<.0001$ & $<.0001$ & $<.0001$ \\
\hline & -0.044 & -0.036 & -0.044 \\
\hline \multirow[b]{2}{*}{ IssuerSize*post2000Dum } & $<.0001$ & 0.000 & $<.0001$ \\
\hline & 0.099 & 0.098 & 0.093 \\
\hline \multirow[b]{2}{*}{ Leverage*post2000Dum } & $<.0001$ & $<.0001$ & $<.0001$ \\
\hline & -0.538 & -0.554 & -0.543 \\
\hline \multirow[b]{2}{*}{ OpMargin*post2000Dum } & $<.0001$ & $<.0001$ & $<.0001$ \\
\hline & 0.006 & 0.006 & 0.006 \\
\hline \multirow[b]{2}{*}{ Stkretstd*post2000Dum } & $<.0001$ & $<.0001$ & $<.0001$ \\
\hline & 0.225 & 0.234 & 0.226 \\
\hline \multirow{2}{*}{ IssueSize*post2000Dum } & 0.020 & 0.016 & 0.020 \\
\hline & 0.009 & 0.009 & 0.006 \\
\hline \multirow{2}{*}{ YTM*post2000Dum } & $<.0001$ & $<.0001$ & 0.007 \\
\hline & -0.005 & -0.004 & -0.010 \\
\hline \multirow[b]{2}{*}{ Seniordum*post2000Dum } & 0.300 & 0.411 & 0.038 \\
\hline & $\begin{array}{l}-0.127 \\
<.0001\end{array}$ & $\begin{array}{l}-0.134 \\
<.0001\end{array}$ & $\begin{array}{l}-0.117 \\
<.0001\end{array}$ \\
\hline \multirow{2}{*}{$\begin{array}{l}\text { Adjusted R-square } \\
\mathrm{N}\end{array}$} & 0.093 & 0.095 & 0.187 \\
\hline & 81,641 & 81,641 & 81,641 \\
\hline
\end{tabular}


Table 7: Robustness

The sample period for Panel A is 1991-2009, while for Panel B is 1999-2001. Panel C presents the results when Fitch's ratings are used as the benchmark. We estimate model (1) on the sample of new bond issues, and model (2) on the sample that includes all outstanding issues. The dependent variables for model (1) and model (2) are RatingDiff and LeadTimeDiff, respectively. RatingDiff is the S\&P numerical rating minus the Moody's numerical rating. LeadTimeDiff is the fraction of a year where Moody's assigns a higher rating minus the fraction of a year where S\&P assigns a higher rating. Post2000Dum is a dummy variable that takes the value of one for the years in the post-public period, and zero otherwise. Other variables are defined as in Table 4. The number below each estimate of the coefficients is heteroscedasticity adjusted robust $p$-value. We cluster standard errors by the issuing firm. ***, **, * represent significance at $1 \%, 5 \%$ and $10 \%$ level, respectively.

\begin{tabular}{|c|c|c|c|c|c|c|}
\hline & \multicolumn{2}{|c|}{$\begin{array}{c}\text { Pane A: } 9 \text { years around } 2000 \\
(1991-2009)\end{array}$} & \multicolumn{2}{|c|}{$\begin{array}{l}\text { Panel B: } 1 \text { year around } 2000 \\
(1999-2001)\end{array}$} & \multicolumn{2}{|c|}{$\begin{array}{l}\text { Panel C: Using Fitch as the } \\
\text { Benchmark }\end{array}$} \\
\hline & $\begin{array}{l}\text { I.New } \\
\text { Issues }\end{array}$ & $\begin{array}{l}\text { II.Outstanding } \\
\text { Issues }\end{array}$ & $\begin{array}{l}\text { III.New } \\
\text { Issues }\end{array}$ & $\begin{array}{l}\text { IV.Outstanding } \\
\text { Issues }\end{array}$ & $\begin{array}{l}\text { V.New } \\
\text { Issues }\end{array}$ & $\begin{array}{l}\text { VI.Outstanding } \\
\text { Issues }\end{array}$ \\
\hline \multirow[t]{2}{*}{ Intercept } & -0.251 & -0.051 & -0.023 & -0.162 & -1.724 & -0.828 \\
\hline & 0.002 & $<.0001$ & 0.931 & $<.0001$ & $<.0001$ & $<.0001$ \\
\hline \multirow[t]{2}{*}{ post2000Dum } & 0.178 & 0.285 & 0.475 & 0.114 & 0.555 & 0.106 \\
\hline & $<.0001$ & $<.0001$ & 0.017 & $<.0001$ & 0.000 & $<.0001$ \\
\hline \multirow[t]{2}{*}{ IssuerSize } & 0.025 & 0.014 & -0.025 & -0.020 & -0.111 & 0.019 \\
\hline & 0.000 & $<.0001$ & 0.375 & $<.0001$ & 0.001 & $<.0001$ \\
\hline \multirow[t]{2}{*}{ Leverage } & 0.128 & 0.078 & -0.697 & -0.171 & -0.651 & 0.461 \\
\hline & 0.084 & $<.0001$ & 0.001 & 0.000 & 0.001 & $<.0001$ \\
\hline \multirow[t]{2}{*}{ OpMargin } & -0.007 & -0.004 & -0.053 & -0.025 & -0.607 & -0.082 \\
\hline & $<.0001$ & 0.002 & 0.000 & 0.020 & 0.148 & $<.0001$ \\
\hline \multirow[t]{2}{*}{ Stkretstd } & -1.552 & 0.004 & -0.231 & -0.260 & -1.665 & -1.160 \\
\hline & $<.0001$ & 0.296 & 0.264 & 0.065 & $<.0001$ & $<.0001$ \\
\hline \multirow[t]{2}{*}{ IssueSize } & 0.006 & 0.006 & 0.054 & 0.000 & -0.037 & -0.075 \\
\hline & 0.444 & $<.0001$ & 0.005 & 0.983 & 0.003 & $<.0001$ \\
\hline \multirow[t]{2}{*}{ YTM } & 8.794 & 0.012 & -17.931 & 0.028 & 37.851 & 0.040 \\
\hline & 0.016 & $<.0001$ & 0.144 & $<.0001$ & $<.0001$ & $<.0001$ \\
\hline \multirow[t]{2}{*}{ SeniorDum } & -0.203 & -0.002 & 0.048 & -0.045 & -0.379 & 0.041 \\
\hline & $<.0001$ & 0.824 & 0.702 & 0.038 & $<.0001$ & $<.0001$ \\
\hline \multirow[t]{2}{*}{ IssuerSize*post2000Dum } & 0.045 & 0.089 & 0.087 & 0.045 & 0.172 & 0.044 \\
\hline & $<.0001$ & $<.0001$ & 0.017 & $<.0001$ & $<.0001$ & $<.0001$ \\
\hline \multirow[t]{2}{*}{ Leverage*post2000Dum } & -0.791 & -0.384 & 1.014 & -0.292 & 0.225 & -0.705 \\
\hline & $<.0001$ & $<.0001$ & 0.003 & $<.0001$ & 0.428 & $<.0001$ \\
\hline \multirow[t]{2}{*}{ OpMargin*post2000Dum } & 0.006 & 0.004 & 0.053 & 0.025 & -0.090 & -0.342 \\
\hline & $<.0001$ & 0.002 & 0.000 & 0.018 & 0.842 & $<.0001$ \\
\hline \multirow[t]{2}{*}{ Stkretstd*post2000Dum } & 1.359 & -0.021 & 1.270 & 0.262 & 2.345 & 1.150 \\
\hline & 0.148 & 0.014 & 0.412 & 0.067 & 0.241 & $<.0001$ \\
\hline \multirow[t]{2}{*}{ IssueSize*post2000Dum } & -0.025 & -0.004 & -0.014 & 0.046 & 0.023 & 0.094 \\
\hline & 0.008 & 0.008 & 0.582 & $<.0001$ & 0.104 & $<.0001$ \\
\hline \multirow[t]{2}{*}{ YTM*post2000Dum } & 6.703 & -0.028 & 17.629 & -0.017 & -14.810 & -0.105 \\
\hline & 0.203 & $<.0001$ & 0.247 & 0.085 & 0.169 & $<.0001$ \\
\hline \multirow[t]{2}{*}{ Seniordum*post2000Dum } & 0.460 & -0.164 & 0.035 & -0.072 & 0.045 & -0.366 \\
\hline & $<.0001$ & $<.0001$ & 0.851 & 0.019 & 0.673 & $<.0001$ \\
\hline Adjusted R-square & 0.145 & 0.090 & 0.092 & 0.042 & 0.194 & 0.117 \\
\hline $\mathrm{N}$ & 11,697 & 137,411 & 1,496 & 15,827 & 5,851 & 32,428 \\
\hline
\end{tabular}

